\title{
BILATERAL SKELETONIZED INTERNAL THORACIC ARTERY GRAFTING IN 303 PATIENTS SEVENTY YEARS AND OLDER
}

\author{
Amir Kramer, MD \\ Menachem Mastsa, MD \\ Yosef Paz, MD \\ Chaim Locker, MD \\ Dimitri Pevni, MD \\ Jacob Gurevitch, MD \\ Itzhak Shapira, MD \\ Oren Lev-Ran, MD \\ Rephael Mohr, MD
}

\begin{abstract}
Objectives: Higher patency rates of the internal thoracic artery have led myocardial revascularization with bilateral internal thoracic arteries to be a procedure designated primarily for young patients. Fewer leg wound complications and sternal collateral flow preservation with the skeletonizing dissection technique can make bilateral internal thoracic artery grafting attractive also for elderly patients.
\end{abstract}

Methods: Between May 1996 and May 1998, 303 consecutive patients aged 70 years or older (mean age 75.5 years; range 70-92 years) underwent coronary artery bypass grafting with double skeletonized internal thoracic arteries. Forty-four $(14.5 \%)$ patients were 80 years or older, and $89(28 \%)$ had diabetes. The mean number of grafts was 3.1 per patient (2-6).

Results: Operative mortality was $2.6 \%(n=8)$ : it was higher for octogenarians $(6.8 \%)$ than for younger patients $(1.9 \%)(P=.06)$. The only significant preoperative predictors of early mortality were complicated percutaneous transluminal coronary angioplasty $(P=.03)$ and preoperative use of intraaortic balloon pumping $(P=.03)$. Six patients $(2 \%)$ had sternal wound infections for which chronic lung disease $(P=.02)$ and emergency operation $(P=.006)$ were the only significant predictors. Twenty-two $(7.2 \%)$ late deaths occurred, and 1- and 3-year survivals were $93 \%$ and $90 \%$, respectively. The 3-year survival of patients 80 years old or older was $92 \%$.

Conclusions: Bilateral grafting of the skeletonized internal thoracic artery carries relatively low morbidity and mortality in elderly patients and can be recommended for selected patients including octogenarians. ( $\mathrm{J}$ Thorac Cardiovasc Surg 2000;120:290-7)
A life expectancy increases, more elderly patients are eing referred for coronary artery bypass grafting (CABG). The current conventional and most commonly used operative procedure for myocardial revascularization in patients of all ages involves one internal thoracic

From the Department of Thoracic and Cardiovascular Surgery, Tel Aviv Sourasky Medical Center, Sackler Faculty of Medicine, Tel Aviv University, Tel Aviv, Israel.

Received for publication Sept 27, 1999; revisions requested Dec 16, 1999; revisions received March 30, 2000; accepted for publication April 4, 2000.

Address for reprints: Rephael Mohr, MD, The Department of Thoracic and Cardiovascular Surgery, Tel Aviv Sourasky Medical Center, 6 Weizmann St, Tel Aviv 64239, Israel (E-mail: shapiraiz@tasmc.health.gov.il).

Copyright (C) 2000 by The American Association for Thoracic Surgery

0022-5223/2000 $\$ 12.00+0 \quad \mathbf{1 2 / 1 / 1 0 7 6 8 5}$

doi: $10.1067 / \mathrm{mtc} .2000 .107685$ artery (ITA) together with one or more saphenous vein grafts (SVGs). ${ }^{1,2}$ The major surgical objective is to supply the left anterior descending (LAD) coronary artery with an ITA to improve the patient's survival. , $^{3,4}$

Since SVG failure is a major drawback of $\mathrm{CABG},{ }^{1}$ surgical techniques that involve minimal use of SVGs were attempted. In most centers, the ITA is isolated from the chest wall as a pedicle, together with the vein, muscle, fat, and accompanying endothoracic fascia. ${ }^{3-5}$ Harvesting is relatively quick because cautery is used to separate the pedicle from the chest wall. However, cauterization damages the blood supply to the sternum which, in turn, impedes sternal healing and exposes the sternum to the risks of early dehiscence and infection in operations involving both ITAs. The risk of sternal infection is particularly high in patients with preoperatively limited sternal blood supply, such as those who are elderly and those who have diabetes. 6,7 
Table I. Patient characteristics and operative mortality $(n=8)$

\begin{tabular}{|c|c|c|c|c|c|c|c|}
\hline \multirow[b]{2}{*}{ Factor } & \multicolumn{2}{|c|}{$\begin{array}{c}\text { Prevalence } \\
(n=303)\end{array}$} & \multicolumn{2}{|c|}{$\begin{array}{l}\text { Mortality } \\
\text { with factor }\end{array}$} & \multicolumn{2}{|c|}{$\begin{array}{c}\text { Mortality } \\
\text { without factor }\end{array}$} & \multirow[b]{2}{*}{$\mathrm{P}$} \\
\hline & No & $\%$ & No & $\%$ & No & $\%$ & \\
\hline Age $\geq 80 y$ & 44 & 14.5 & 3 & 6.8 & 5 & 1.9 & .06 \\
\hline Female sex & 89 & 29.4 & 3 & 3.4 & 5 & 2.3 & .7 \\
\hline Left main stenosis & 99 & 31.8 & 2 & 2.1 & 6 & 2.8 & 1.0 \\
\hline Acute $\mathrm{MI}<1 \mathrm{wk}$ & 91 & 30 & 2 & 2.2 & 6 & 2.8 & 1.0 \\
\hline Old MI & 114 & 37.6 & 3 & 2.6 & 5 & 2.6 & 1.0 \\
\hline Complicated PTCA & 28 & 9.2 & 3 & 10.7 & 5 & 1.8 & .03 \\
\hline $\mathrm{EF} \leq 35 \%$ & 61 & 20.1 & 3 & 4.9 & 5 & 2.1 & .2 \\
\hline $\mathrm{CHF}$ & 59 & 18.5 & 3 & 5.1 & 5 & 2 & .2 \\
\hline Preoperative IABP & 11 & 3.6 & 2 & 18.2 & 6 & 2.1 & .03 \\
\hline Diabetes & 89 & 27.7 & 2 & 2.4 & 6 & 2.7 & 1.0 \\
\hline Hypertension & 156 & 51.5 & 3 & 1.9 & 5 & 3.4 & .5 \\
\hline PVD & 16 & 5.3 & 0 & 0 & 8 & 2.8 & 1.0 \\
\hline Chronic renal failure & 39 & 12.9 & 0 & 0 & 8 & 3 & .6 \\
\hline Severe COPD & 32 & 10.6 & 3 & 9.3 & 5 & 1.8 & .07 \\
\hline Emergency surgery & 22 & 7.3 & 4 & 18.2 & 4 & 1.4 & .11 \\
\hline Repeat CABG & 13 & 4.3 & 0 & 0 & 8 & 2.7 & 1.0 \\
\hline Surgical technique (cross) & 73 & 24.1 & 3 & 4.1 & 5 & 2.2 & .41 \\
\hline Surgical technique (composite) & 204 & 67.3 & 4 & 2 & 4 & 4 & .44 \\
\hline Sequential grafts & 117 & 67.6 & 2 & 1.7 & 6 & 3.2 & 1.0 \\
\hline Use of GEA & 60 & 19.8 & 1 & 1.7 & 7 & 2.9 & 1.0 \\
\hline Use of SVG & 30 & 9.9 & 0 & 0 & 8 & 2.9 & 0.6 \\
\hline
\end{tabular}

$M I$, Myocardial infarction; $P T C A$, percutaneous transluminal coronary angioplasty; $E F$, ejection fraction; $C H F$, congestive heart failure; $I A B P$, intra-aortic balloon pump; $P V D$, peripheral vascular disease; $C O P D$, chronic obstructive pulmonary disease; $C A B G$, coronary artery bypass grafting; $G E A$, gastroepiploic artery; $S V G$, saphenous vein graft.

A surgical technique was recently developed wherein the ITA is dissected as a skeletonized vessel. ${ }^{8,9}$ The skeletonized artery is isolated gently with scissors and silver clips, without the use of cauterization. Skeletonized ITA dissection leaves the vein, muscle, and accompanying tissue in place. The advantages are that the dissected ITA is longer and that its spontaneous blood flow is greater than that of the pedicled ITA, ${ }^{10}$ allowing the use of both ITAs as grafts to all necessary coronary vessels. No additional vein grafts are required in most cases. ${ }^{11}$ Another advantage of using the ITA as a skeletonized artery is the preservation of collateral blood supply to the sternum, enabling more rapid healing and decreasing the risk of infection. ${ }^{12}$

The bilateral skeletonized ITA technique was adopted in our service as the preferred method for myocardial revascularization. The routine use of SVGs was stopped in April 1996, and they are currently used as a third optional graft (the second is the right gastroepiploic artery) or in emergency CABG operations. ${ }^{13}$

Between May 1996 and May 1998, 781 consecutive patients underwent $\mathrm{CABG}$ with bilateral skeletonized ITAs. In this report, we analyze the early and midterm results of a subgroup of elderly patients in whom this surgical technique was used.

\section{Patients and methods}

Between May 1996 and May 1998, 303 consecutive patients 70 years or older underwent CABG by means of the bilateral skeletonized ITA technique. They comprised $38 \%$ of the 781 patients who underwent CABG surgery with bilateral skeletonized ITAs during this period in the Tel Aviv Sourasky Medical Center.

The patients' preoperative and operative characteristics are listed in Table I. The ITAs were dissected as skeletonized arteries ${ }^{9}$ before heparin administration to decrease the risk of damage and hematoma formation in the region of the side branches during dissection.

Injury to the ITAs was extremely uncommon, happening mainly during the learning curve period. The reasons for this low occurrence of injury are as follows:

1. The work is delicate and refined and takes longer to perform than the standard technique

2. Cautery, which might cause direct or indirect injury, is not used

3. The technique of skeletonized ITA dissection is performed routinely and daily in our operating rooms

Operations were performed with cardiopulmonary bypass. The myocardial preservation technique involved intermittent warm cardioplegia $\left(30^{\circ}-32^{\circ} \mathrm{C}\right) .{ }^{14}$ Our strategies for complete arterial revascularization are detailed in a recently published study by Gurevitch and associates. ${ }^{15}$ 

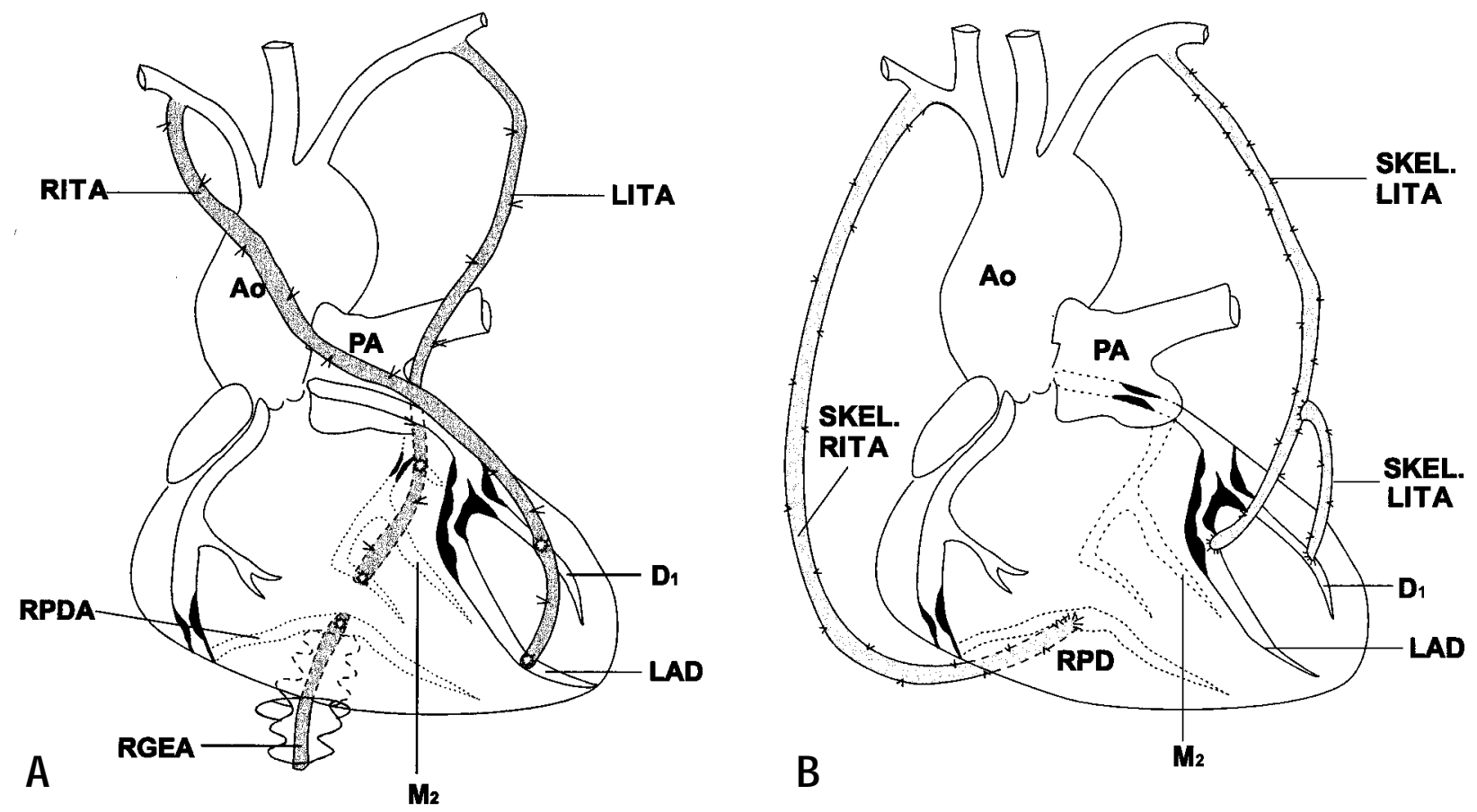

Fig 1. A, The cross arrangement with 2 ITAs and the gastroepiploic artery. B, In situ right ITA to the right coronary artery and the left ITA to the LAD artery with a small composite graft. RITA, Right internal thoracic artery; $L I T A$, left internal thoracic artery; $A o$, aorta; $P A$, pulmonary artery; $R P D$ and $R P D A$, right posterior descending artery; $R G E A$, right gastroepiploic artery; $L A D$, left anterior descending artery; $D_{1}$, first diagonal branch; $M_{2}$, second marginal branch. (Reproduced [with modifications] with permission from He GW, editor. Arterial graft for coronary artery bypass surgery. Singapore: Springer-Verlag Singapore Pte Ltd; 1999.)

We prefer to use bilateral ITAs as in situ grafts for myocardial revascularization. The 2 ITAs in combination with the right gastroepiploic artery give us 3 sources of blood supply. We believe that more blood sources are associated with improved long-term outcome. The cross arrangement (Fig 1, $A$ ) is based on the assumption that patency rate of the right ITA on the LAD coronary artery is similar to that of the left ITA on the LAD. ${ }^{16,17}$ To improve late survival, one should make every effort to use both ITA grafts for the left system..$^{5,17,18}$ In 60 patients (20\%), the right gastroepiploic artery was used as a third arterial conduit to bypass the posterior descending branch of the right coronary artery (Fig 1, $A$ ).

We do not use the cross technique in patients with a short right ITA, very long ascending aorta, enlarged right ventricle, too distal or unpredictable LAD anastomotic site, or a high probability of future reoperations (eg, combined aortic valve replacement and CABG). In most of these patients (204 patients) we use the composite arterial grafting technique.

The composite graft can be prepared before connection to cardiopulmonary bypass. Most of the composite grafts included end-to-side anastomosis of the free right ITA on an in situ left ITA (Fig 2, A). To date, injury to the ITA necessitating a revision of the original operative plan has occurred in fewer than $5 \%$ of our patients; in most, except for a very few cases, the operation can still be based on both ITAs.
If injury is caused to the proximal right ITA, the operation can still be based on constructing a composite graft, wherein the free right ITA graft is anastomosed end to side to the in situ left ITA. The operative plan is changed in these cases only when our original plan was to use the "cross" technique.

If the proximal left ITA is injured, a reverse composite graft can be constructed, with the free left ITA being connected end to side to the in situ right ITA. This arrangement of a free left ITA on in situ right ITA can also be used when the spontaneous free flow of the left ITA is inadequate (Fig 2, B).

When no graft to the posterior wall of the heart (the circumflex region) was necessary (26 patients), the left ITA was grafted to the LAD and the right ITA to the right coronary artery or its posterior descending branch (Fig 1, B). In most cases, it is impossible to reach this branch with the right ITA graft when using the regular technique of isolating the pedicled ITA. The skeletonized right ITA, however, is longer and, therefore, can usually reach the better-quality distal posterior descending artery. Another variation of composite grafting was the small Y-graft, wherein a small distal section of an ITA was anastomosed end to side to a more proximal part of the same artery (Fig 1, B).

The small Y-graft was performed in 35 patients in all 3 groups. In most cases it was used for LAD diagonal grafting. 

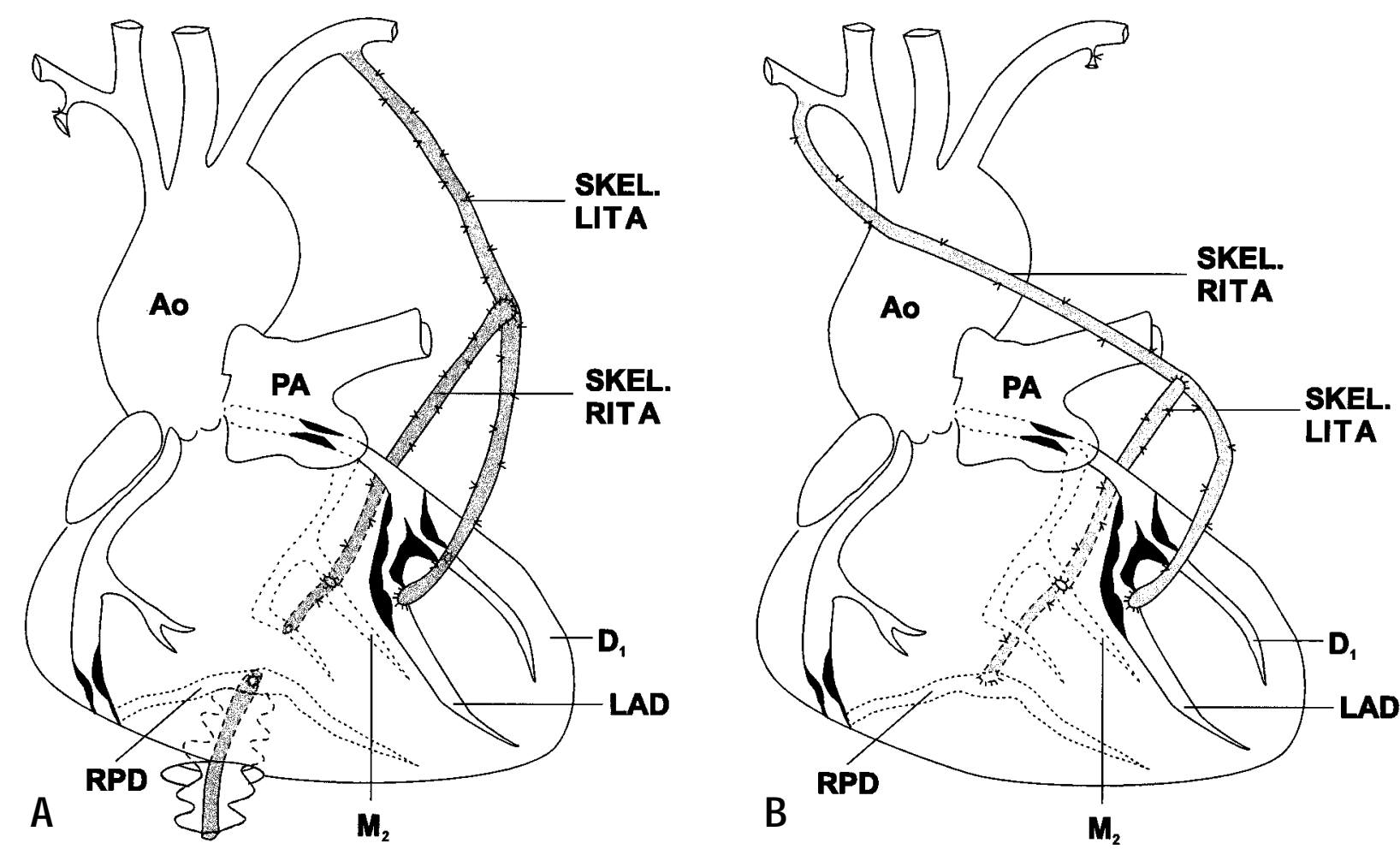

Fig 2. A, Composite arrangements for bilateral ITA grafting: composite graft to the LAD and the circumflex arteries, and gastroepiploic artery to the posterior descending artery. B, Composite arrangements for bilateral ITA grafting: end-to-side anastomosis of free left ITA to in situ right ITA. For abbreviations, see Fig 1. (Reproduced [with modifications] with permission from He GW, editor. Arterial graft for coronary artery bypass surgery. Singapore: SpringerVerlag Singapore Pte Ltd; 1999.)

In 2 cases it was used for an intermediate branch, and in 1 the left ITA was anastomosed to the first marginal and the Y-graft to the intermediate branch.

Our current preference is to use the small Y-graft for the LAD diagonal branch when we do not need grafts to the circumflex system. In cases that require grafts to the circumflex system, the left ITA is anastomosed to the LAD, and the diagonal is one of the vessels supplied by the right ITA (sequential grafting).

To decrease the risk of spasm of the arterial grafts, we treated all patients with high-dose intravenous infusion of isosorbide dinitrate (Isoket, $4-20 \mathrm{mg} / \mathrm{h}$ ) during the first 24 to 48 hours after the operation. ${ }^{19}$ Systolic blood pressure was maintained above 100 to $120 \mathrm{~mm} \mathrm{Hg}$. From the second postoperative day, the patients whose gastroepiploic artery was used were treated with calcium channel blockers (diltiazem, 90$180 \mathrm{mg}$ /day orally) for at least 3 months.

Statistical analysis. Data are expressed as mean \pm standard deviation or proportions. The Fisher exact test and 2-sample $t$ tests were used to compare discrete and continuous variables, respectively. The multivariate Cox proportional hazard model was used to evaluate the influence of preoperative variables on overall mortality (early plus late).

The log-rank test was performed twice to examine the effect of the operation on short-term survival. The first test specifically compared 1-year survivals and the second test (a global test) compared 3-year survivals.

Postoperative survival was expressed by the Kaplan-Meier method and survival curves were compared by the log-rank test. All analyses were performed with SPSS 7.5 software (SPSS, Inc, Chicago, Ill).

\section{Results}

The 303 elderly patients in the study received from 2 to 6 grafts (mean 3.1) each. The average cardiopulmonary bypass time was $77.9 \pm 36$ minutes, and aortic crossclamping time was $62 \pm 29$ minutes. Operative mortality (30 days postoperatively) was $2.6 \%$ (8 patients) (Table I). The mortality of the octogenarians was higher $(6.8 \%)$ than that of the younger patients $(1.9 \%)(P=.06)$. Postoperative morbidity included perioperative myocardial infarction in $7(2.3 \%)$ patients and stroke in $8(2.6 \%)$ patients (4 were left with permanent neurologic deficiency and 4 recovered completely). Six patients $(2.0 \%)$ had a sternal wound infection, 1 of whom was included in the perioperative mortality data. Seven patients $(2.3 \%)$ had postoperative bleeding that required reopening the chest. 
Table II. Patients' characteristics and deep sternal infection $(n=6)$

\begin{tabular}{lccccc}
\hline & \multicolumn{2}{c}{ Sternal infection with factor } & & \multicolumn{2}{c}{ Sternal infection without factor } \\
\cline { 2 - 3 } \multicolumn{1}{c}{ Factor } & No. & $\%$ & No. & \% & P (Fisher exact test) \\
\hline Age $\geq 80$ y & 1 & 2.3 & 5 & 1.9 & 1.0 \\
Female sex & 3 & 3.4 & 3 & 1.4 & .4 \\
EF $\leq 35 \%$ & 2 & 3.3 & 4 & 1.7 & .3 \\
CHF & 2 & 3.4 & 6 & 2.1 & .3 \\
Preoperative IABP & 0 & 0 & 5 & 2.3 & 1.0 \\
Diabetes & 1 & 1.2 & 5 & 1.9 & 1.0 \\
Chronic renal failure & 1 & 2.6 & 3 & 1.1 & .6 \\
Severe COPD & 3 & 9.4 & 3 & 1.1 & .02 \\
Emergency surgery & 3 & 13.6 & 6 & 2.1 & 0.006 \\
Repeat CABG & 0 & 0 & 5 & 1.00 \\
\hline
\end{tabular}

$E F$, Ejection fraction; $C H F$, congestive heart failure; $I A B P$, intra-aortic balloon pump; $C O P D$, chronic obstructive pulmonary disease; $C A B G$, coronary artery bypass grafting.

Analysis of preoperative characteristics of the 8 patients who had a stroke revealed that 5 of them had diabetes. The risk of postoperative stroke among these elderly patients with diabetes was $6 \%(5 / 89)$ compared with a $1.4 \%(3 / 219)$ risk of stroke in patients without diabetes $(P=.03)$. The use of SVGs in a cohort of elderly patients was also associated with postoperative stroke, but SVGs were used in only $9.9 \%$ of the patients (30 patients); of these, $3(10 \%)$ had a stroke, compared with $5(1.8 \%)$ of the 273 patients who received complete arterial revascularization without the use of vein grafting $(P=.02)$.

The influence of the various preoperative risk factors on postoperative sternal infection is shown in Table II: the only significant risk factors in this cohort of elderly patients were chronic obstructive pulmonary disease (COPD) and emergency operation.

Follow-up information up to 40 months postoperatively was available in 283 of the 295 surviving patients (97\%). There were 22 late deaths, 8 of which were unrelated to the operation. Three patients had a late myocardial infarction and 2 patients reported the early return of angina. Twenty patients underwent cardiac catheterization during the follow-up period, 2 because of chest pain, and the remainder consented to elective catheterization within the framework of our learning to use the composite graft. Fifty-nine of 64 distal ITA anastomoses (92\%) were patent.

Analysis of the entire cohort showed 1- and 3-year survivals of $93 \%$ and $90 \%$, respectively. The 1-year survival of octogenarians was not significantly different from that of the younger patients (87\% vs $94 \%$ ). However, the survival of the younger age group was significantly better after 3 years $(92 \pm 0.02$ vs $74 \pm$ $0.07, P=.0002)(\mathrm{n}=30)($ Fig 3$)$.
Analysis of both early and late mortality events showed the following preoperative variables to be independent predictors of overall mortality: COPD (hazard ratio $=5.1 ; 95 \%$ confidence intervals $=1.9-13.7)$, age more than 80 years (hazard ratio $=4.0 ; 95 \%$ confidence intervals $=1.6-10.1)$, ejection fraction less than $35 \%$ (hazard ratio $=3.1 ; 95 \%$ confidence intervals $=$ 1.3-7.8).

\section{Discussion}

Use of the left ITA as a bypass graft has been shown to result in better early patency and improved survival in all patients, including elderly ones, ${ }^{20}$ but most published series failed to show additional survival benefit with bilateral ITA grafting. ${ }^{1,2}$

The lack of survival benefits and the technical complexity in performing complete arterial revascularization with bilateral ITAs are the probable reasons for the relative lack of popularity of this technique. For example, the New York State Cardiac Surgery database for 1996 reported 19,659 isolated CABG cases, of which only $1554(8 \%)$ involved bilateral ITA grafting. ${ }^{21}$ The Society of Thoracic Surgery (STS) database included 153,000 CABG operations, of which only $4 \%$ involved bilateral ITAs. $^{21}$

In contrast to most of the previously published reports, 3 important large-scale studies have shown that long-term survival with bilateral ITAs is better than that with a single ITA. Lytle and associates ${ }^{22}$ reported that the 10- and 15-year survivals of patients undergoing bilateral ITA grafting were $84 \%$ and $67 \%$ compared with $79 \%$ and $64 \%$, respectively, for patients with single ITA grafts $(P<.001)$. Reoperative and angina-free survivals, as well as freedom from additional revascularization procedures, were significantly higher in the 


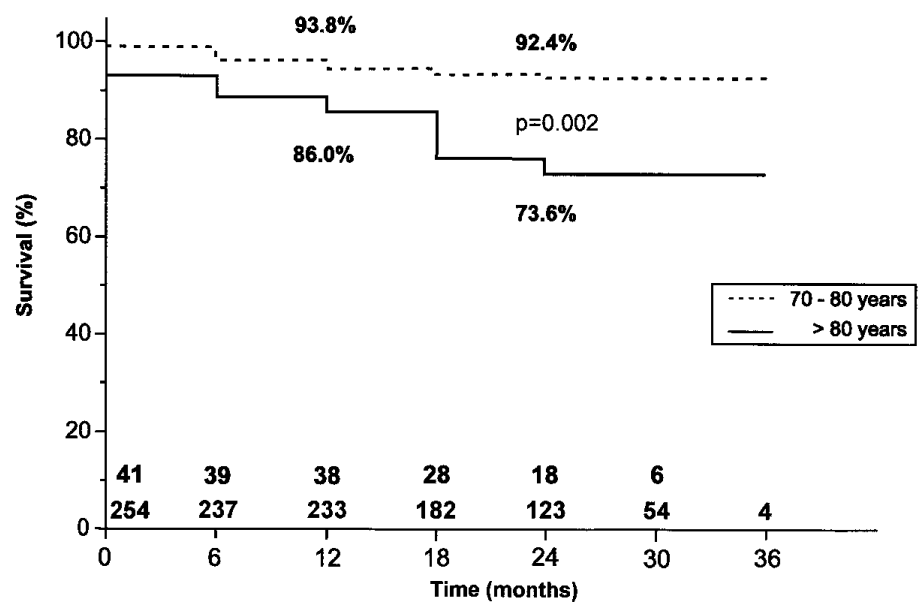

Fig 3. Comparison of survival curves (Kaplan-Meier) of octogenarians and younger patients. (Reproduced with permission from He GW, editor. Arterial graft for coronary artery bypass surgery. Singapore: Springer-Verlag Singapore Pte Ltd; 1999.)

bilateral ITA subset. ${ }^{22}$ In another study performed by Buxton and associates, ${ }^{23}$ the 10 -year actuarial survival of patients receiving bilateral ITA grafts was $86 \% \pm$ $3 \%$, compared with $71 \% \pm 5 \%$ for those receiving a single ITA graft $(P<.001)$. In that report, the use of bilateral ITAs improved the rate of freedom from late myocardial infarction and reoperations. In the third report, Schmidt and colleagues ${ }^{5}$ demonstrated that survival benefit with bilateral ITA operations is achieved by grafting the ITA conduits to coronary arteries supplying the left ventricle rather than the right coronary system.

The use of bilateral ITA grafts in elderly patients is controversial. He and coworkers ${ }^{24}$ reported an operative mortality of $24 \%$ in elderly patients ( $\geq 70$ years) who underwent bilateral ITA grafting. Moreover, use of bilateral ITA grafts in the older patients in their report was found to be a major risk factor for operative mortality, since mortality in the patients receiving 1 ITA was only $6.8 \%(P<.007)$. The ITA in their report was used as a pedicled conduit and, as they stated, the fact that only $4 \%$ of the patients received bilateral ITA grafts might have explained the higher operative mortality and increased use of postoperative intra-aortic balloon pumping $(16.2 \%$ vs $5.9 \%, P<.02)$.

In a study by Lytle and associates, ${ }^{22}$ the number of patients older than 60 years operated on with bilateral ITA grafts was relatively small; however, bilateral ITA grafting improved survival of this subset of older patients when compared with patients older than 60 years with a single ITA graft.

In all the above series, extensive arterial grafting with bilateral ITAs was used preferentially in a selected group of young male non-obese nondiabetic patients. ${ }^{5,22-24}$ The only large series (1467 patients) comparing bilateral with single ITA grafting in elderly patients was reported by Galbut and associates. ${ }^{25}$ In this study, patients with bilateral ITAs had a lower hospital mortality $(3.1 \%)$ than patients with a single ITA (6.4\%), and the late survival (mean 43 months) was better as well (69.7\% vs $60.7 \%)$.

Most studies reporting results of bilateral ITA grafting contain small numbers of patients operated on over a relatively long period. ${ }^{5,22-24}$ Patients were preselected for this procedure according to their life expectancy, and few of the patients older than 70 years were offered the option of bilateral ITA grafting. Unlike those reports, our series and that of Galbut and coworkers ${ }^{25}$ describe results in a nonselected group of patients. Complete arterial grafting with bilateral ITAs was the preferred method of myocardial revascularization for all ages during the 24-month study period. Bilateral ITA grafting was performed in $71 \%$ of the patients referred for $\mathrm{CABG}$ during this period, and $38 \%$ of them were 70 years or older.

Mortality and morbidity of our patients 70 years or older $(2.6 \%)$ compared favorably with mortality described in procedures in which one ITA was used. ${ }^{1}$ Although the mortality of octogenarians was higher $(6.8 \%)$ than that of patients younger than 80 years $(1.9 \%)$, the difference did not reach statistical significance.

In the report by Lytle and colleagues, ${ }^{22}$ the only morbid event that differed between the bilateral and single ITA groups was the difference in sternal wound complication $(2.5 \%$ and $1.4 \%$, respectively). Harvesting the 
ITA as a wide muscular fascial pedicle with the aid of electrocautery was shown to devascularize sternal collateral blood supply and expose the sternum to increased risk of poor healing, dehiscence, and infection. ${ }^{6}$ Our report conferred significant clinical support to the assumption that the skeletonized ITA technique causes less damage to the sternal blood flow ${ }^{8,26}$ and, therefore, our rates of sternal infections and complications with bilateral ITA grafting are in the lower ranges of those reported by others. Despite the fact that the sternum of elderly patients is sometimes more fragile because of osteoporosis and suboptimal blood supply, old age in this report was not found to be associated with an increased occurrence of sternal infections. The occurrence of sternal infection in patients older than 80 years was $2.3 \%$ (1 patient), compared with $1.9 \%$ (5 patients) in patients between 70 and 80 years. On the other hand, increased occurrence of sternal infection in this report was found in patients with chronic lung disease. Increased respiratory forces causing high suture line pressure can probably explain the increased occurrence of sternal complications in this subgroup of elderly patients.

Another interesting finding of our study is the increased occurrence of postoperative stroke in patients with diabetes, which was 4 times higher than that in patients who did not have diabetes (6\% vs $1.4 \%$ ). Diabetes mellitus and the use of SVGs were the only predictors of postoperative stroke identified in this cohort of 303 elderly patients with bilateral ITA grafting. However, in this series SVGs were used in only a small group of patients.

In a recently published multicenter prospective study on 2108 patients, Roach and coworkers ${ }^{27}$ reported an occurrence of $6.1 \%$ for adverse cerebral outcome and $3.1 \%$ for strokes (fatal and nonfatal) after CABG. The occurrence of strokes was 5 times as high in patients with intraoperative palpable atherosclerotic plaque in the proximal aorta. Despite the older age of the patients in our present report (mean age 75.5 years, with 44 of them $\geq 80$ years), the occurrence of postoperative stroke was similar to that in the report by Roach's group $^{27}(2.6 \%$ vs $3.1 \%)$. This may be explained by the fact that complete arterial revascularization was achieved without the use of vein grafting in $90 \%$ of the patients.

Complete arterial revascularization without vein grafting limits aortic manipulations to aortic cannulation, crossclamping, and insertion of the cardioplegia needle. Atherosclerosis of the aorta and large vessels, including those of the brain, affects more older patients and is more severe and extensive in patients with diabetes than in those without diabetes. ${ }^{28}$ The diffuse and advanced nature of the atherosclerotic plaques in the aorta and brain vessels of the elderly patients with diabetes is probably the best explanation for the higher incidence of stroke in this subset of patients in our report. Another possible explanation is the elevated level of $\beta$-thromboglobulin and circulating platelet aggregates in their blood, which may reflect platelet activation and cause microemboli postoperatively. ${ }^{29}$ The midterm results of this study include up to 3 years of follow-up. The decreased survival after emergency operations probably results from the relatively high operative mortality. The increased operative mortality and sternal infections necessitating sternectomy and long-term hospitalization among patients with COPD were the main causes of decreased survival in this subset of patients. Age 80 years or older was also associated with decreased late survival; however, the difference in survival became significant only 2 years after the operation. This suggests that late mortality of octogenarians may be related to factors other than the operative procedure, such as the life expectancy of individuals of such advanced age.

In conclusion, the skeletonizing dissection technique enables safe performance of complete arterial revascularization with bilateral ITAs in patients 70 years or older. This new surgical technique is associated with a low rate of sternal infection because of preservation of sternal collateral blood supply. Morbidity associated with leg wound incisions - an integral part of saphenous vein harvesting - was circumvented. We therefore recommend the routine use of bilateral skeletonized ITA grafting for most patients 70 years and older. The technique should not be used in emergency operations or in patients with COPD who bear an increased risk of sternal infection.

We thank Esther Eshkol for editorial assistance.

\section{REFERENCES}

1. Lytle BW, Cosgrove DM. Coronary artery bypass surgery. Curr Probl Surg 1992;29:733-807.

2. Leavitt BJ, Olmstead EM, Plume SK, Charlesworth DC, Maislen EL, James TW, et al. Use of the internal mammary artery graft in Northern New England Cardiovascular Disease Study Group. Circulation 1997;96(Suppl):II-6

3. Loop FD, Lytle BW, Cosgrove DM, Stewart RW, Goormastic M, Williams W, et al. Influence of the internal-mammary-artery graft on 10-year survival and other cardiac events. $\mathrm{N}$ Engl J Med 1986;314:1-6

4. Barner HB, Standeven JW, Reese J. Twelve-year experience with internal mammary artery for coronary artery bypass. J Thorac Cardiovasc Surg 1985;90:668-75. 
5. Schmidt SE, Jones JW, Thornby JI, Miller CC, Beall AC Jr. Improved survival with multiple left-sided bilateral internal thoracic artery grafts. Ann Thorac Surg 1997;64:9-14.

6. Carrier M, Gregoire J, Tronc F, Cartier R, Leclerc Y, Pelletier LC. Effect of internal mammary artery dissection on sternal vascularization. Ann Thorac Surg 1992;53:115-9.

7. He GW, Acuff TE, Ryan WH, Mack MJ. Risk factors for operative mortality in elderly patients undergoing internal mammary artery grafting. Ann Thorac Surg 1994;57:1453-60.

8. Parish MA, Asai T, Grossi EA, Gallaway AC, Golvin SB, et al. The effects of different techniques of internal mammary artery harvesting on sternal blood flow. J Thorac Cardiovasc Surg 1992;104:1303-7.

9. Cunningham JM, Gharavi MA, Fardin R, Meek RA. Considerations in the skeletonization technique of internal thoracic artery dissection. Ann Thorac Surg 1992;54:947-50.

10. Choi JB, Lee SY. Skeletonized and pedicled internal thoracic artery grafts: effects on free flow during bypass. Ann Thorac Surg 1996;61:909-13.

11. Tector AJ, Kress DC, Downey FX, Schmahl TM. Complete revascularization with internal thoracic artery grafts. Semin Thorac Cardiovasc Surg 1996;8:29-41.

12. Sauvage LR, Wu HD, Kowalsky TE, Davis CC, Smith JC, Rittenhause EA, et al. Healing basis and surgical techniques for complete revascularization of the left ventricle using only the internal mammary arteries. Ann Thorac Surg 1986;42:449-65.

13. Sofer D, Gurevitch J, Shapira I, Paz Y, Mastsa M, Kramer A, et al. Sternal wound infection in patients after coronary artery bypass grafting using bilateral skeletonized internal mammary arteries. Ann Surg 1999;229:585-90.

14. Calafiore AM, Teodori G, Mezzette A, Bosco G, Verna AM, Di Giammarco G, et al. Intermittent antegrade warm blood cardioplegia. Ann Thorac Surg 1995;59:398-402.

15. Gurevitch J, Kramer A, Locker C, Shapira I, Paz Y, Matsa M, et al. Technical aspects of double-skeletonized internal mammary artery grafting. Ann Thorac Surg 2000;69:841-6.

16. Dion R, Etienne PY, Verhelst GD, Khoury G, Rubay J, Bettendorff $P$, et al. Bilateral mammary grafting: clinical, functional and angiographic assessment in 400 consecutive patients. Eur J Cardiothorac Surg 1993;7:287-94.

17. Pick AW, Orszulak TA, Anderson BJ, Schaff HV. Single versus bilateral internal mammary artery grafts: 10 -year outcome analysis. Ann Thorac Surg 1997;64:599-605.

18. Sergeant P, Flameng W, Suy R. The sequential internal mammary artery graft: long term results of a consecutive series of 364 patients. J Cardiovasc Surg (Torino) 1988;29:596-600.

19. Gurevitch J, Miller HI, Shapira I, Kramer A, Paz Y, Matsa M, et al. High-dose isosorbide dinitrate for myocardial revascularization with complete arterial grafts. Ann Thorac Surg 1997;63:382-7.

20. Morris RJ, Strong MD, Grunewald KE, Kuretu ML, Samuels LE, Kresh JY, et al. Internal thoracic artery for coronary artery grafting in octogenarians. Ann Thorac Surg 1996;62:16-22.

21. Loop FD. Coronary artery surgery: the end of the beginning. Eur J Cardiothorac Surg 1998;14:554-71.

22. Lytle BW, Arnold JH, Loop FD, Akhrass RMK, Houghtaling PL, Blackstone $\mathrm{EH}$, et al. Two internal thoracic artery grafts are better than one. J Thorac Cardiovasc Surg 1999;117:855-72.

23. Buxton BF, Komeda M, Fuller JA, Gordon I. Bilateral internal thoracic artery grafting may improve outcome of coronary artery surgery. Circulation 1998;98(Suppl):II-1-6.

24. He GW, Acuff TE, Ryan WH, Mack MJ. Risk factors for operative mortality in elderly patients undergoing internal mammary artery grafting. Ann Thorac Surg 1994;57:1453-60.

25. Galbut DL, Traad EA, Dorman MJ, DeWitt PL, Larsen PB, Kuransky PA, et al. Coronary bypass grafting in the elderly: single versus bilateral internal mammary artery grafting. J Thorac Cardiovasc Surg 1993;106:128-35.

26. Cohen AJ, Lockman J, Lorberboym M, Bder O, Cohen N, Medalion $\mathrm{B}$, et al. Assessment of sternal vascularity with single photon emission computed tomography after harvesting of the internal thoracic artery. J Thorac Cardiovasc Surg 1999;118:496-502.

27. Roach GW, Kanchuger GW, Mangano CM, Newman M, Nussemeier N, Wolman L, et al. Adverse cerebral outcome after coronary bypass surgery. N Engl J Med 1996;335:1857-63.

28. Waller BF, Palumbo PJ, Kie JT, Roberts WC. Studies of the coronary arteries at necropsy in diabetes mellitus with onset after age 30 years: analysis of 229 diabetic patients with and without clinical evidence of coronary heart disease and comparison to 183 control subjects. Am J Med 1980;69:498-506.

29. Preston FE, Ward JD, Marcola PH, Porter NR, Timperley WR, O'Malley BC. Elevated beta-thromboglobulin levels and circulating platelet aggregates in diabetic microangiopathy. Lancet 1978;1:238-40. 